\title{
Peripheral quantitative computed tomography (PQCT) predicts humeral diaphysis torsional mechanical properties with good short-term precision
}

\author{
Alyssa M. Weatherholt ${ }^{1}$, Keith G. Avin ${ }^{1,2}$, Andrea L. Hurd ${ }^{1}$, Jacob L. Cox ${ }^{3}$, Scott T. \\ Marberry $^{3}$, Brandon G. Santoni ${ }^{3}$, and Stuart J. Warden ${ }^{*}, 1,2$ \\ ${ }^{1}$ Center for Translational Musculoskeletal Research, School of Health and Rehabilitation \\ Sciences, Indiana University, Indianapolis, IN, USA \\ ${ }^{2}$ Department of Physical Therapy, School of Health and Rehabilitation Sciences, Indiana \\ University, Indianapolis, IN, USA \\ ${ }^{3}$ Phillip Spiegel Orthopaedic Research Laboratory, Foundation for Orthopaedic Research and \\ Education, Tampa, FL, USA
}

\begin{abstract}
Peripheral quantitative computed tomography (pQCT) is a popular tool for non-invasively estimating bone mechanical properties. Previous studies have demonstrated pQCT provides precise estimates that are good predictors of actual bone mechanical properties at popular distal imaging sites (tibia and radius). The predictive ability and precision of pQCT at more proximal sites remains unknown. The aim of the current study was to explore the predictive ability and short-term precision of pQCT estimates of mechanical properties of the midshaft humerus, a site gaining popularity for exploring the skeletal benefits of exercise. Predictive ability was determined ex vivo by assessing the ability of pQCT-derived estimates of torsional mechanical properties in cadaver humeri (density-weighted polar moment of inertia $\left[\mathrm{I}_{\mathrm{P}}\right]$ and polar Strength Strain Index $\left[\mathrm{SSI}_{\mathrm{P}}\right]$ ) to predict actual torsional properties. Short-term precision was assessed in vivo by performing six repeat pQCT scans at the level of the midshaft humerus in 30 young, healthy individuals (degrees of freedom $=150$ ), with repeat scans performed by the same and different testers and on the same and different days to explore the influences of different testers and time between repeat scans on precision errors. $\mathrm{I}_{\mathrm{P}}$ and $\mathrm{SSI}_{\mathrm{P}}$ both independently predicted at least $90 \%$ of the variance in ex vivo midshaft humerus mechanical properties in cadaveric bones. Overall values for relative precision error (root mean squared coefficients of variation) for in vivo measures of $\mathrm{I}_{\mathrm{P}}$ and $\operatorname{SSI}_{\mathrm{P}}$ at the midshaft humerus were less than $1.5 \%$ and were not influenced by $\mathrm{pQCT}$ assessments being performed by different testers or on different days. These data indicate that pQCT provides very good prediction of midshaft humerus mechanical properties with good short-
\end{abstract}

(C) 2014 by the International Society for Clinical Densitometry. All rights reserved

*Address correspondence to: Stuart J. Warden, PT, PhD, FACSM, School of Health and Rehabilitation Sciences, Indiana University, 1140 W. Michigan Street, CF-120, Indianapolis, IN 46202, USA. stwarden@iu.edu.

Publisher's Disclaimer: This is a PDF file of an unedited manuscript that has been accepted for publication. As a service to our customers we are providing this early version of the manuscript. The manuscript will undergo copyediting, typesetting, and review of the resulting proof before it is published in its final citable form. Please note that during the production process errors may be discovered which could affect the content, and all legal disclaimers that apply to the journal pertain. 
term precision, with measures being robust against the influences of different testers and time between repeat scans.

\section{Keywords}

bone density; bone size; least significant change; peripheral quantitative computed tomography (pQCT); reproducibility

\section{Introduction}

Peripheral quantitative computed tomography (pQCT) uses a small purpose-built scanner to obtain tomographic images of the extremities. It has the advantage over dual-energy X-ray absorptiometry (DXA) of being able to image bone tissue in three dimensions which allows assessment of volumetric density and cross-sectional structure. These measures may have advantages in estimating bone size and strength. For instance, pQCT-derived strength estimates improved fracture prediction beyond that provided by DXA-derived areal bone mineral density (aBMD) alone (1). Also, pQCT may reveal novel observations that may otherwise be missed with the sole use of DXA. For example, pQCT was recently used to demonstrate that exercise completed when young had lasting benefits on bone size and estimated strength, despite loss of DXA-derived bone mass benefits (2).

To facilitate the use of pQCT, it needs to provide precise measures that predict actual bone properties. Previous studies explored the predictive ability and short-term precision of pQCT measures of estimated bone strength at popular imaging sites-tibial and radial diaphyses and distal metaphyses (3-15). At diaphyseal sites, pQCT provides bone strength estimates via calculation of cross-sectional moments of inertia and section moduli. Multiplication of these structural-based measures by the quotient of pQCT measured cortical density and physiologic density $\left(1200 \mathrm{mg} / \mathrm{cm}^{3}\right)$ is used to account for the influence of bone material properties, with the density-weighted section modulus provided by pQCT referred to as the Strength Strain Index (SSI) (16). SSI (and analogous pQCT-derived strength estimates) of the radial and tibial diaphyses have been shown to be relatively predictive and precise, predicting $66-98 \%$ of the variance in the ability to resist bending forces (7-915) and having root mean squared coefficients of variation (RMS-CV) typically $<2.5 \%$ (4-611-14).

While pQCT provides predictive and precise estimates of bone mechanical properties at distal imaging sites, its predictive ability and precision at more proximal sites remains unknown. The upper arm is a proximal site popular for pQCT imaging as the humeral diaphysis is a frequent site for exploring the skeletal effects of exercise (217-23). It is possible that precision of pQCT measures of the upper arm is less than at distal sites due to a combination of factors, including heightened difficulty repetitively positioning subjects further than usual within the machine gantry, greater potential for subtle movement artifacts due to difficulty stabilizing the proximal end of the bone against subtle trunk motions, and a larger limb volume than present distally which heightens beam hardening and reduces pQCT precision (1213). In support of possibly reduced pQCT precision when imaging the upper arm, preliminary work by Sievänen et al. (12) reported a RMS-CV of 5.6\% for estimated strength measures of the midshaft humerus. 
The current study aimed to explore the predictive ability and short-term precision of pQCT estimates of midshaft humerus mechanical properties. Predictive ability was determined $e x$ vivo by assessing the ability of pQCT-derived estimates of torsional mechanical properties in cadaver humeri to predict actual torsional properties. Short-term precision was assessed in vivo by six repeat $\mathrm{pQCT}$ scans performed at the level of the midshaft humerus in 30 young, healthy individuals, with repeat scans performed by the same and different testers and on the same and different days to explore the influences of different testers and time between repeat scans on precision errors.

\section{Methods}

\section{Ex vivo predictive ability}

Specimens and imaging-Unilateral humeri were dissected from 20 fresh human cadavers following Institutional Review Board approval. The bones were cleaned of softtissues, wrapped in saline-soaked dressings, and stored at $-20^{\circ} \mathrm{C}$. Prior to imaging, humeri were thawed to room temperature and measured for length. Each humerus was positioned in the gantry of a Stratec XCT 3000 machine equipped with software version 6.20C (Stratec Medizintechnik GmbH, Pforzheim, Germany). A scout scan was performed and a reference line placed at the inferior aspect of the capitulum. A tomographic slice (thickness $=2.3 \mathrm{~mm}$; voxel size $=300 \mu \mathrm{m}$; scan speed $=20 \mathrm{~mm} / \mathrm{s}$ ) was taken at $50 \%$ of humeral length from the reference line. The specimens were kept moist during imaging via saline-soaked dressings.

Each tomographic slice was analyzed to obtain bone mineral density, structure, and estimated strength. Cortical mode 1 (threshold, $710 \mathrm{mg} / \mathrm{cm}^{3}$ ) was used to obtain cortical volumetric bone mineral density (Ct.vBMD, $\mathrm{mg} / \mathrm{cm}^{3}$ ), bone mineral content (Ct.BMC, $\mathrm{mg}$ / $\mathrm{mm}$ ), and area $\left(\mathrm{Ct} . \mathrm{Ar}, \mathrm{cm}^{2}\right)$. Total area (Tt.Ar, $\left.\mathrm{cm}^{2}\right)$, periosteal (Ps.Pm, $\mathrm{mm}$ ) and endocortical (Ec.Pm, $\mathrm{mm}$ ) perimeters, and average cortical thickness (Ct.Th, $\mathrm{mm}$ ) were obtained by analyzing the slices using contour mode 1 (threshold, $710 \mathrm{mg} / \mathrm{cm}^{3}$ ) to define the outer bone edge and peel mode 2 (threshold, $400 \mathrm{mg} / \mathrm{cm}^{3}$ ) to separate the cortical and subcortical/medullary compartments. Thickness and perimeter measures used a circular ring model, and medullary area $\left(\mathrm{mm}^{2}\right)$ was derived as total area minus cortical area. Bone strength was estimated by the density-weighted polar moment of inertia $\left(\mathrm{I}_{\mathrm{P}}, \mathrm{mm}^{4}\right)$ and polar SSI $\left(\mathrm{SSI}_{\mathrm{P}}, \mathrm{mm}^{3}\right)$ obtained using cortical mode $2\left(\right.$ threshold $\left.=400 \mathrm{mg} / \mathrm{cm}^{3}\right)$.

Mechanical Testing-Mechanical testing was performed at room temperature with the specimens kept moist via saline irrigation. The ends of each humerus were potted in aluminum potting boxes using high strength resin (Bondo Body Filler; 3M Collision Repair Solutions, St. Paul, MN USA). The boxes were rigidly coupled to a servohydraulic materials testing machine (Bionix; MTS Systems Corporation, Eden Prairie, MN) equipped with an axial/torsional load cell rated to $\pm 25 \mathrm{kN}$ (axial load) and \pm 250 N.m (torsional load) (Fig. 1A). The longitudinal axis of the diaphysis was aligned with the load frame and a $20 \mathrm{~N}$ axial compressive preload applied. The proximal humerus was externally rotated in displacement control at $10 \%$ until failure. Data were collected at $50 \mathrm{~Hz}$. Biomechanical parameters of interest included maximum torque at failure (N.m) and torsional rigidity (N.m/ $\left.{ }^{\circ}\right)$ (Fig. 1B). 


\section{In vivo short-term precision}

Subjects-A convenience sample of 30 young, healthy subjects was recruited. Young, healthy individuals were assessed as they are frequently the focus of studies exploring the skeletal effects of exercise at the humeral diaphysis (217-23). Subjects were included if they were $\geq 18$ years of age and not pregnant. Subjects presented for repeat testing on 2 separate days, a minimum of 1 week apart. Height, weight and humeral length were measured, and pQCT performed during the first study visit. During the second study visit, only humeral length was measured and pQCT performed. Assessments were performed on the nondominant arm. The study was approved by the Institutional Review Board and all subjects provided informed consent.

Anthropometric measures-Humeral length was measured using a sliding anthropometer as the distance between the lateral border of the acromion and the radiohumeral joint line. Humeral length was measured during each study visit by two testers to determine within- and between-tester and within- and between-day reproducibility. The mean of the measures during the first study visit was used as humeral length for localization of all pQCT scans.

PQCT_Six scans of the humerus were performed using the same pQCT machine and scanning parameters as used to image cadaver specimens. Four scans were performed during the first visit, with each tester performing two scans with interim repositioning. During the second visit, each tester performed one scan each. For scanning, subjects were positioned supine with their arm in $90^{\circ}$ shoulder abduction and centered in the pQCT machine gantry. A concave, padded holder was placed under the arm for support and elastic restraints placed around the supracondylar region and surgical neck of the humerus to minimize movement. A scout scan was performed to observe the radiohumeral joint, a reference line placed through the joint at the distal edge of the humeral capitulum, and a tomographic slice taken at $50 \%$ of humeral length from the reference line.

Each tomographic slice was analyzed as described for the cadaveric specimens to obtain bone mineral density, structure, and estimated strength. In addition, each slice was analyzed to obtain soft tissue composition at the level of midshaft humerus using contour mode 3 (threshold, $-100 \mathrm{mg} / \mathrm{cm}^{3}$ ) to locate the skin surface and peel mode 2 (threshold, $40 \mathrm{mg} / \mathrm{cm}^{3}$ ) to locate the subcutaneous fat-muscle boundary. A F03F05 filter was used to remove noise. Soft tissue variables of interest included total tissue cross-sectional area (CSA, $\left.\mathrm{mm}^{2}\right)$, absolute $\left(\mathrm{cm}^{2}\right)$ and relative $(\%)$ muscle and fat CSA, and muscle density $\left(\mathrm{mg} / \mathrm{cm}^{3}\right)$.

Statistical analyses-Statistical analyses were performed using IBM SPSS Statistics for Windows (v22.0; IBM Corp., Armonk, NY) with a level of significance set at 0.05. Linear regression analysis assessed the ability of pQCT-derived measures to predict cadaver humeri mechanical properties, with the fit of each univariate model assessed using coefficients of determination $\left(\mathrm{R}^{2}\right)$. Within- and between-tester and within- and between-day agreement for humeral length measures were determined via intraclass correlation coefficients (ICC [2,1]). The RMS method was used to compute the overall standard deviation (RMS-SD, expressed in the respective unit of measure) and coefficient of variation (RMS-CV, \%) of the precision 
error of pQCT measures for the six replicate scans in the 30 subjects (total degrees of freedom = 150). RMS-SD and RMS-CV are referred to as absolute and relative precision, respectively. The absolute and relative LSC at the $95 \%$ confidence level were derived for each RMS-SD and RMS-CV precision error estimate by multiplying by 2.77 , respectively (24). To determine the influence of tester and timing on pQCT precision, two-way factorial analyses of variance (ANOVAs) were performed on individual subject absolute precision error measurements (SD) for the following subgroups of duplicate scans: 1) within-tester and within-day; 2) between-tester and within-day; 3) within-tester and between-day, and; 4) between-tester and within-day.

\section{Results}

\section{Ex vivo predictive ability}

Cadavers had varying characteristics resulting in the acquirement of humeri with a range of pQCT and mechanical properties (Table 1). None of the humeri exhibited any visible signs of injury or pathology. All of the humeri failed via a spiral-type fracture (Fig. 2). Fractures initiated at the mid-diaphysis in the majority of humeri $(n=13)$, while fractures initiating in the proximal and distal diaphysis occurred in 3 and 4 humeri, respectively. Ct.BMC, Tt.Ar, Ct.Ar and Ps.Pm predicted $61 \%-85 \%$ of the variance in maximum torque and torsional rigidity, while Ct.Th predicted 35\%-50\% (all $P<0.01$, Table 2). Ct.vBMD did not predict humeri torsional mechanical properties (all $P=0.43-0.74$ ). $\mathrm{I}_{\mathrm{P}}$ and $\mathrm{SSI}_{\mathrm{P}}$ both independently explained over $90 \%$ of the variance in maximum torque and torsional rigidity (all $P<0.001$, Fig. 3).

\section{In vivo short-term precision}

Subject characteristics are shown in Table 1. There was high within- and between-tester, and within- and between-day agreement for humeral length measures (all ICC [2,1] $r \geq 0.98$ ). The overall absolute and relative precision measurements and the respective absolute and relative LSC values at the $95 \%$ confidence level are given in Table 3. The relative RMS for all six replicate scans ranged from $0.47-1.44 \%$ for bone measures and $0.70-2.75 \%$ for soft-tissue measures. The subsequent relative LSC values ranged from 1.29-3.99\% for bone measures and $1.95-7.63 \%$ for soft-tissue measures.

The influences of tester and timing on the precision of pQCT measures are provided in Table 4. There were no significant tester by timing interactions on precision for any measure meaning that the two variables had independent effects on precision error (all $P=0.07-0.96$ ). There was a significant main effect for tester on precision of Ct.vBMD $(P<0.01)$; however, tester had no significant main effect on precision for any other measure (all $P=0.25-0.94$ ) indicating that the measures performed by the two different testers were equally precise. Timing had a significant effect on precision measures for total tissue CSA, absolute muscle CSA and absolute fat CSA (all $P<0.05$ ) with between day measures being less precise.

\section{Discussion}

The current data indicate $\mathrm{pQCT}$ provides very good prediction of midshaft humerus mechanical properties with good short-term precision. $\mathrm{I}_{\mathrm{P}}$ and $\mathrm{SSI}_{\mathrm{P}}$ predicted at least $90 \%$ of 
the variance in torsional mechanical properties of cadaver humeri. Previous studies exploring the ability of pQCT measures to predict bone mechanical properties exclusively exposed bones to bending and/or axial compressive forces (37-1015). Bending and compression are common directions of bone loading, but the measurement of high shear strains when completing functional tasks in in vivo strain gauge experiments indicates the presence of significant torsional loads (25). Torsional loading of the humerus is thought to be particularly prominent due to counteracting torques being applied at the shoulder and elbow ends of the bone, and contributes to exaggerated humeral head retroversion and the occurrence of spiral-type humeral diaphysis fractures in the dominant arm of overhead athletes (223). To our knowledge, only one previous study has explored the ability of pQCT to predict bone torsional mechanical properties. Lind et al. (26) observed $\mathrm{SSI}_{\mathrm{P}}$ predicted $15 \%$ and $33 \%$ of maximal torque and torsional rigidity in rodent humeri, respectively. These values are much lower than in the current study; however, data collected from rodent humeri are not comparable to those obtained from cadaveric humeri due to the presence of a variable, yet large deltoid tuberosity in rodents and generally greater difficulty torsional testing rodent sized bones.

Bone mechanical properties are influenced by the amount, distribution and intrinsic properties of bone material present in the direction of loading. As SSIP and density-weighted $\mathrm{I}_{\mathrm{P}}$ take into account each of these contributors as they relate to resisting torques around a central axis, it is not surprising that $\mathrm{SSI}_{\mathrm{P}}$ and $\mathrm{I}_{\mathrm{P}}$ were both better predictors of ex vivo torsional mechanical properties than independent measures of bone mass, structure or intrinsic properties. $\mathrm{SSI}_{\mathrm{P}}$ and $\mathrm{I}_{\mathrm{P}}$ both independently predicted $\geq 90 \%$ of ex vivo mechanical properties and, thus, either can be used to predict mechanical properties of the midshaft humerus. However, $\mathrm{SSI}_{\mathrm{P}}$ was a slightly better predictor than $\mathrm{I}_{\mathrm{P}}$. This observation is consistent with Wilhelm et al. (15) who found SSI $_{P}$ to predict slightly more of the variance in fracture load of cadaveric radii during three-point bending than $\mathrm{I}_{P}(98 \%$ vs. $94 \%)$. SSI $P$ and $\mathrm{I}_{\mathrm{P}}$ are related, with $\mathrm{SSI}_{\mathrm{P}}$ calculated as $\mathrm{I}_{\mathrm{P}}$ divided by the maximum distance of the furthest voxel to the torsional axis. As greatest shear stresses during torsional loading are experienced in material furthest from the loading axis, incorporation of the distance of the most extreme voxels from the torsional axis by $\operatorname{SSI}_{\mathrm{P}}$ enables it provide a slightly better prediction of mechanical properties than $\mathrm{I}_{\mathrm{P}}$.

The current work demonstrates that $\mathrm{pQCT}$ is able to provide in vivo measures of the midshaft humerus in young, healthy individuals with good short-term precision. Measures with small precision errors allow the detection of small differences over time or between groups, ultimately reducing study sample sizes to detect a desired difference. Precision errors for skeletal measures of the midshaft humerus were up to double those we previously reported for measures performed of the tibial diaphysis (13). Reasons for the higher shortterm precision errors of pQCT measures of the humeral diaphysis were not assessed; however, possible explanations include those described in the introduction with regards to imaging more proximal skeletal sites (i.e. heightened difficulty positioning subjects further within the machine gantry and greater potential for subtle movement artifacts). Another possible explanation for lower precision of $\mathrm{PQCT}$ measures of the midshaft humerus in the current study is the performance of scans by different assessors than those in our previous 
work. However, one assessor in the current study (A.L.H.) was very experienced performing pQCT scans of the midshaft humerus having previously performed several hundred scans and both assessors (A.M.W. and A.L.H.) were equally precise suggesting assessor experience was not a contributing factor.

Despite precision errors for $\mathrm{pQCT}$ scans of the midshaft humerus being higher than those previously shown for the tibial diaphysis, they were still low $(<1.5 \%)$ and within acceptable levels for bone densitometry (27). In addition, they were substantially lower than those reported by Sievänen et al. (12) who reported a RMS-CV of 5.6\% for estimated strength measures of the midshaft humerus. Reasons for our better short-term precision compared to Sievänen et al. (12) are not clear; however, there are differences between our respective studies. Limb positioning and stabilization procedures differed between the studies which can influence the potential for movement artifacts. However, a greater occurrence of subtle movement artifacts in the study by Sievänen et al. (12) is unlikely to explain their higher precision error as movement artifacts impact on Ct.vBMD measures and short-term precision of Ct.vBMD in our respective studies were comparable ( $0.5 \%$ vs. $0.5 \%)$. Sievänen et al. (12) estimated midshaft humerus mechanical properties via the calculation of a bone strength index which was calculated as $\mathrm{I}_{\mathrm{P}}$ multiplied by $\mathrm{pQCT}$ measured Ct.vBMD. This method of density-weighting differs to current methods which involve multiplying $\mathrm{SSI}_{P}$ or $\mathrm{I}_{\mathrm{P}}$ by the quotient of pQCT measured Ct.vBMD and physiologic density. However, the use of physiologic density to normalize Ct.vBMD essentially introduces a constant factor that does not influence precision measures. Both studies followed the recommendations of the ISCD which state that short-term precision error for densitometry assessments should obtained using the root mean square (RMS) approach from an assessment with 30 degrees of freedom (2728). However, overall precision error in the current study was determined from a higher number of degrees of freedom compared to Sievänen et al. (12) (150 vs. 31 degrees of freedom), with degrees of freedom potentially influencing precision estimates and degrees of freedom higher than recommended by the ISCD providing greater confidence in the precision estimate (29).

The current work had a number of strengths, including testing of cadaveric humeri in a novel, yet functional direction, determination of overall precision errors using a large number of degrees of freedom, and investigation of the influences of different testers and time between repeat scans on precision errors. There are also several limitations that warrant acknowledgement. During torsional testing of the cadaveric humeri, not all bones failed at the midshaft where pQCT imaging was performed. However, the ability of pQCT measures to predict mechanical properties were very good despite the discrepancies between the imaging and bone failure locations possibly negatively impacting predictive relationships. Precision values reported are for the testing protocol utilized and may not be representative of different protocols. This includes the use of different scanning parameters (including voxel size) and analysis techniques (including thresholding). Finally, the precision values in the current study are limited to the subject population and anatomical site assessed. It is not possible to extrapolate the data to $\mathrm{pQCT}$ measures at alternate sites or populations with differing characteristics, including age, size and musculoskeletal health status. 
Overall, this study found pQCT provides very good prediction of midshaft humerus mechanical properties with good short-term precision. Density-weighted $\mathrm{I}_{\mathrm{P}}$ and $\mathrm{SSI}_{\mathrm{P}}$ both provided predicted actual midshaft humerus torsional mechanical properties, and precision errors for skeletal measures were generally robust against the influences of different testers and time between repeat scans. Based on these data, investigators performing $\mathrm{pQCT}$ measures of the midshaft humerus can have confidence in the utility of pQCT in obtaining estimates of midshaft humerus mechanical properties.

\section{Acknowledgements}

This work was supported by National Institutes of Health (NIH) Grant R01 AR057740.

\section{References}

1. Sheu Y, Zmuda JM, Boudreau RM, et al. Bone strength measured by peripheral quantitative computed tomography and the risk of nonvertebral fractures: the osteoporotic fractures in men (MrOS) study. J Bone Miner Res. 2011; 26:63-71. [PubMed: 20593412]

2. Warden SJ, Mantila Roosa SM, Kersh ME, et al. Physical activity when young provides lifelong benefits to cortical bone size and strength in men. Proc Natl Acad Sci U S A. 2014; 111:5337-42. [PubMed: 24706816]

3. Ashe MC, Khan KM, Kontulainen SA, et al. Accuracy of pQCT for evaluating the aged human radius: an ashing, histomorphometry and failure load investigation. Osteoporos Int. 2006; 17:124151. [PubMed: 16683179]

4. Duckham RL, Frank AW, Johnston JD, Olszynski WP, Kontulainen SA. Monitoring time interval for pQCT-derived bone outcomes in postmenopausal women. Osteoporos Int. 2013; 24:1917-22. [PubMed: 23344257]

5. Giangregorio L, Lala D, Hummel K, Gordon C, Craven BC. Measuring apparent trabecular density and bone structure using peripheral quantitative computed tomography at the tibia: precision in participants with and without spinal cord injury. J Clin Densitom. 2013; 16:139-46. [PubMed: 22981715]

6. Groll O, Lochmuller EM, Bachmeier M, Willnecker J, Eckstein F. Precision and intersite correlation of bone densitometry at the radius, tibia and femur with peripheral quantitative CT. Skeletal Radiol. 1999; 28:696-702. [PubMed: 10653365]

7. Kontulainen SA, Johnston JD, Liu D, Leung C, Oxland TR, McKay HA. Strength indices from pQCT imaging predict up to $85 \%$ of variance in bone failure properties at tibial epiphysis and diaphysis. J Musculoskelet Neuronal Interact. 2008; 8:401-9. [PubMed: 19147978]

8. Liu D, Manske SL, Kontulainen SA, et al. Tibial geometry is associated with failure load ex vivo: a MRI, pQCT and DXA study. Osteoporos Int. 2007; 18:991-7. [PubMed: 17268944]

9. Lochmuller EM, Lill CA, Kuhn V, Schneider E, Eckstein F. Radius bone strength in bending, compression, and falling and its correlation with clinical densitometry at multiple sites. J Bone Miner Res. 2002; 17:1629-38. [PubMed: 12211433]

10. Muller ME, Webber CE, Bouxsein ML. Predicting the failure load of the distal radius. Osteoporos Int. 2003; 14:345-52. [PubMed: 12730737]

11. Rinaldi G, Wisniewski CA, Setty NG, Leboff MS. Peripheral quantitative computed tomography: optimization of reproducibility measures of bone density, geometry, and strength at the radius and tibia. J Clin Densitom. 2011; 14:367-73. [PubMed: 21723765]

12. Sievänen H, Koskue V, Rauhio A, Kannus P, Heinonen A, Vuori I. Peripheral quantitative computed tomography in human long bones: evaluation of in vitro and in vivo precision. $\mathrm{J}$ Bone Miner Res. 1998; 13:871-82. [PubMed: 9610752]

13. Swinford RR, Warden SJ. Factors affecting short-term precision of musculoskeletal measures using peripheral quantitative computed tomography (pQCT). Osteoporos Int. 2010; 21:1863-70. [PubMed: 20052457] 
14. Szabo KA, Webber CE, Gordon C, Adachi JD, Tozer R, Papaioannou A. Reproducibility of peripheral quantitative computed tomography measurements at the radius and tibia in healthy preand postmenopausal women. Can Assoc Radiol J. 2011; 62:183-9. [PubMed: 20576400]

15. Wilhelm, G.; Felsenberg, D.; Bogusch, G.; Willnecker, J.; Thaten, J.; Gummert, P. Biomechanical examinations for validation of the Bone Strength-Strain Index SSI, calculated by peripheral quantitative computed tomography. In: Lyrithis, GP., editor. Musculoskeletal Interactions. Hylonome; Athens: 1999. p. 105-11.

16. Stratec. XCT 3000 Manual Software Version 6.20. Stratec Medizintechnik GmbH; Pforzheim, Germany: 2009.

17. Bogenschutz ED, Smith HD, Warden SJ. Mid-humerus adaptation in fast pitch softballers and the impact of throwing mechanics. Med Sci Sports Exerc. 2011; 43:1698-706. [PubMed: 21311354]

18. Haapasalo H, Kontulainen S, Sievanen H, Kannus P, Jarvinen M, Vuori I. Exercise-induced bone gain is due to enlargement in bone size without a change in volumetric bone density: a peripheral quantitative computed tomography study of the upper arms of male tennis players. Bone. 2000; 27:351-7. [PubMed: 10962345]

19. Ireland A, Maden-Wilkinson T, McPhee J, et al. Upper limb muscle-bone asymmetries and bone adaptation in elite youth tennis players. Med Sci Sports Exerc. 2013; 45:1749-58. [PubMed: 23475166]

20. Kontulainen S, Sievanen H, Kannus P, Pasanen M, Vuori I. Effect of long-term impact-loading on mass, size, and estimated strength of humerus and radius of female racquet-sports players: a peripheral quantitative computed tomography study between young and old starters and controls. J Bone Miner Res. 2003; 18:352-9. [PubMed: 12568413]

21. Nikander R, Sievanen H, Uusi-Rasi K, Heinonen A, Kannus P. Loading modalities and bone structures at nonweight-bearing upper extremity and weight-bearing lower extremity: a pQCT study of adult female athletes. Bone. 2006; 39:886-94. [PubMed: 16731064]

22. Shaw CN, Stock JT. Habitual throwing and swimming correspond with upper limb diaphyseal strength and shape in modern human athletes. Am J Phys Anthropol. 2009; 140:160-72. [PubMed: 19358297]

23. Warden SJ, Bogenschutz ED, Smith HD, Gutierrez AR. Throwing induces substantial torsional adaptation within the midshaft humerus of male baseball players. Bone. 2009; 45:931-41. [PubMed: 19647807]

24. Glüer C-C, Blake G, Lu Y, Blunt B, Jergas M, Genant H. Accurate assessment of precision errors: how to measure the reproducibility of bone densitometry techniques. Osteoporos Int. 1995; 5:26270. [PubMed: 7492865]

25. Yang PF, Bruggemann GP, Rittweger J. What do we currently know from in vivo bone strain measurements in humans? J Musculoskelet Neuronal Interact. 2011; 11:8-20. [PubMed: 21364270]

26. Lind PM, Lind L, Larsson S, Orberg J. Torsional testing and peripheral quantitative computed tomography in rat humerus. Bone. 2001; 29:265-70. [PubMed: 11557371]

27. Schousboe JT, Shepherd JA, Bilezikian JP, Baim S. Executive summary of the 2013 International Society for Clinical Densitometry Position Development Conference on bone densitometry. J Clin Densitom. 2013; 16:455-66. [PubMed: 24183638]

28. Baim S, Wilson CR, Lewiecki EM, Luckey MM, Downs RW Jr. Lentle BC. Precision assessment and radiation safety for dual-energy X-ray absorptiometry: position paper of the International Society for Clinical Densitometry. J Clin Densitom. 2005; 8:371-8. [PubMed: 16311420]

29. Leslie WD, Moayyeri A, Sadatsafavi M, Wang L. A new approach for quantifying change and test precision in bone densitometry. J Clin Densitom. 2007; 10:365-9. [PubMed: 17888697] 

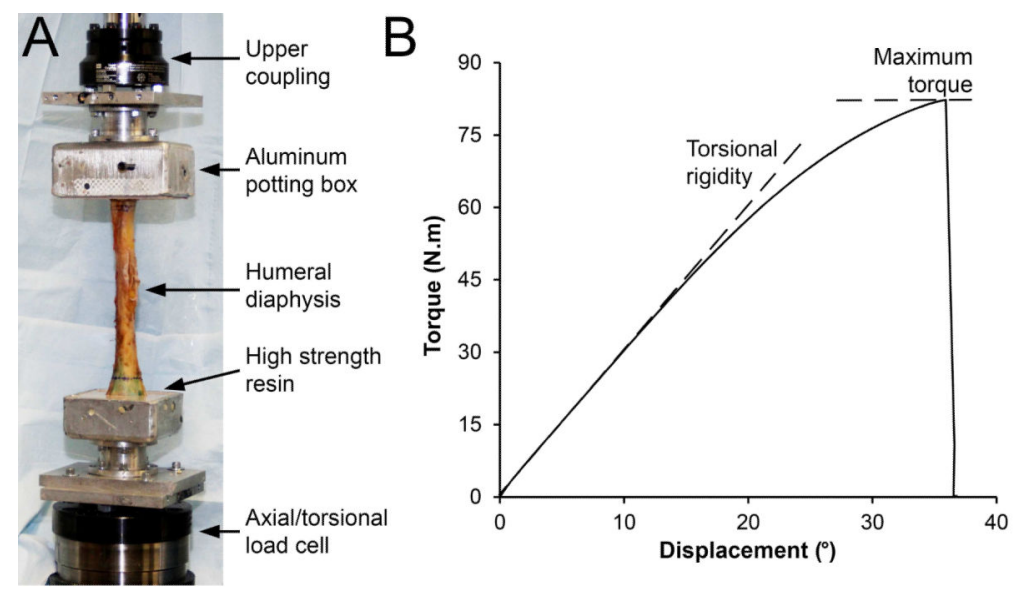

Figure 1.

A) Experimental set-up for torsional mechanical testing of the humeral diaphysis. B) Representative torque-displacement curve generated from torsional testing of a cadaveric humerus. Properties derived from the curve were maximum torque at failure (peak of the curve on the $y$-axis) and torsional rigidity (slope of the linear portion of the curve). 

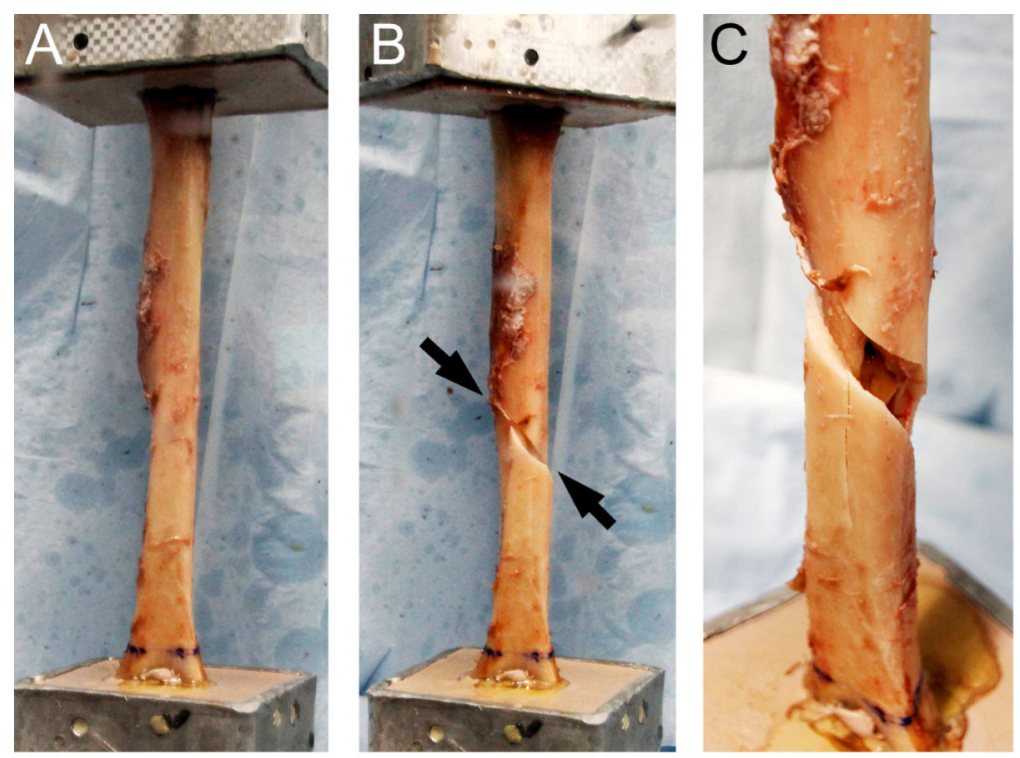

Figure 2.

Spiral-type fracture of the humeral diaphysis during torsional mechanical testing. A) Humeral diaphysis prior to mechanical testing. B) Spiral-type fracture (arrows) of the humeral diaphysis following external rotation of the humeral head. C) Magnified view of the fracture shown in B. 

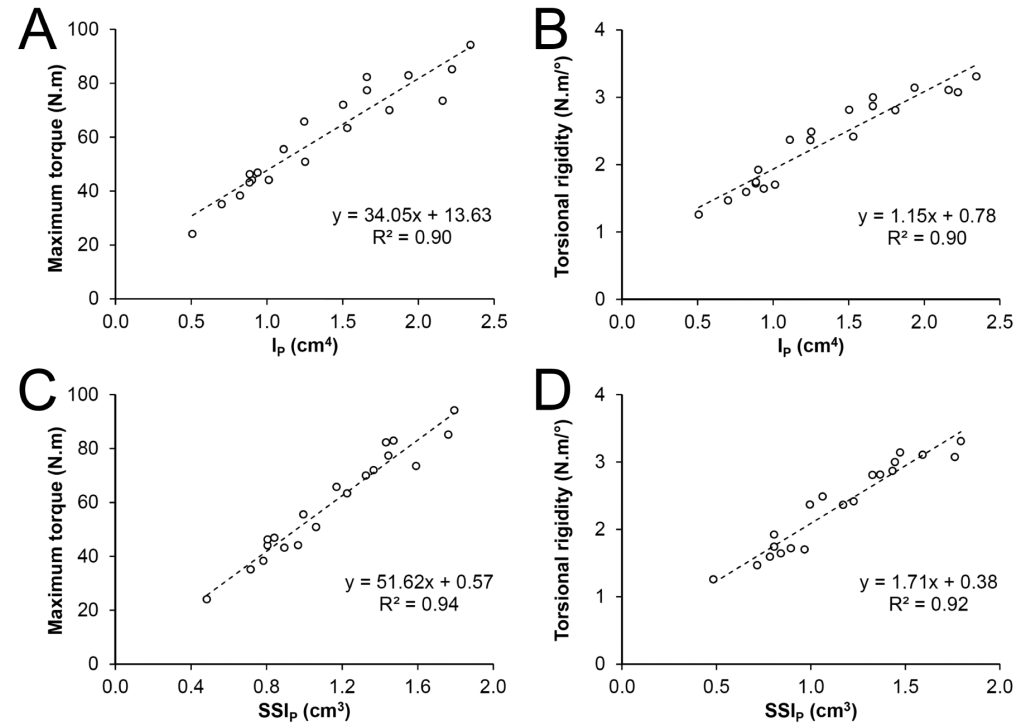

Figure 3.

Scatterplots illustrating the relationship between pQCT-derived estimated strength (densityweighted polar moment of inertia $\left[\mathrm{I}_{\mathrm{P}}\right.$; panels A,B] and polar Strength Strain Index [SSIP; panels $\mathrm{C}, \mathrm{D}]$ ) and cadaver humeri mechanical properties (maximum torque [panels $\mathrm{A}, \mathrm{C}$ ] and torsional rigidity [panels $\mathrm{B}, \mathrm{D}])$. 


\section{Table 1}

Characteristics of the cadavers and subjects used in the ex vivo predictive ability and In vivo short-term precision studies, respectively

\begin{tabular}{|c|c|c|c|c|}
\hline & \multicolumn{2}{|c|}{ Cadavers } & \multicolumn{2}{|c|}{ Subjects ${ }^{a}$} \\
\hline & Mean \pm SD & Range & Mean \pm SD & Range \\
\hline \multicolumn{5}{|l|}{ Cadaver characteristics } \\
\hline $\operatorname{Sex}(\mathrm{M}: \mathrm{F})$ & 10:10 & - & $16: 14$ & - \\
\hline Age (yr) & $72.1 \pm 16.8$ & $24-91$ & $25.7 \pm 6.5$ & $21-29$ \\
\hline Height (m) & $1.69 \pm 0.11$ & $1.50-1.83$ & $1.73 \pm 0.10$ & $1.50-1.92$ \\
\hline Weight $(\mathrm{kg})$ & $70.4 \pm 11.9$ & $40.9-90.9$ & $73.4 \pm 13.7$ & $48.7-108.7$ \\
\hline BMI $\left(\mathrm{kg} / \mathrm{m}^{2}\right)$ & $24.8 \pm 4.1$ & $18.2-32.5$ & $24.3 \pm 3.3$ & $18.5-34.9$ \\
\hline \multicolumn{5}{|l|}{ Humeri pQCT properties } \\
\hline Ct.vBMD $\left(\mathrm{mg} / \mathrm{cm}^{3}\right)$ & $1215 \pm 52$ & $1104-1296$ & $1184 \pm 33$ & $1112-1241$ \\
\hline Ct.BMC $(\mathrm{mg} / \mathrm{mm})$ & $213.8 \pm 65.1$ & $98.0-343.6$ & $261.6 \pm 56.4$ & $174.4-366.7$ \\
\hline Tt.Ar $\left(\mathrm{cm}^{2}\right)$ & $3.04 \pm 0.64$ & $2.12-4.38$ & $3.25 \pm 0.76$ & $2.19-5.38$ \\
\hline Ct.Ar $\left(\mathrm{cm}^{2}\right)$ & $1.76 \pm 0.51$ & $0.84-2.77$ & $2.21 \pm 0.51$ & $1.44-3.20$ \\
\hline Ct.Th (mm) & $3.49 \pm 1.04$ & $1.82-5.28$ & $4.46 \pm 0.74$ & $2.86-6.04$ \\
\hline Ps.Pm (mm) & $61.3 \pm 6.4$ & $51.6-74.2$ & $63.6 \pm 7.3$ & $52.5-82.1$ \\
\hline Ec.Pm (mm) & $39.1 \pm 7.6$ & $24.9-55.8$ & $35.5 \pm 6.4$ & $27.5-56.6$ \\
\hline $\mathrm{I}_{\mathrm{P}}\left(\mathrm{cm}^{4}\right)$ & $1.37 \pm 0.54$ & $0.51-2.34$ & $1.70 \pm 0.72$ & $0.74-3.60$ \\
\hline $\operatorname{SSI}_{\mathrm{P}}\left(\mathrm{cm}^{3}\right)$ & $1.16 \pm 0.37$ & $0.48-1.79$ & $1.35 \pm 0.43$ & $0.76-2.35$ \\
\hline \multicolumn{5}{|l|}{ Humeri mechanical properties } \\
\hline Maximum Torque (N.m) & $60.6 \pm 19.5$ & $24.1-94.2$ & - & - \\
\hline Torsional Rigidity $\left(\mathrm{N} . \mathrm{m} /{ }^{\circ}\right)$ & $2.37 \pm 0.66$ & $1.26-3.31$ & - & - \\
\hline
\end{tabular}

${ }^{a}$ Data in each subject determined from average of six replicate scans 


\section{Table 2}

Coefficients of determination $\left(\mathrm{R}^{2}\right)$ between $\mathrm{pQCT}$ measures and torsional mechanical properties in cadaver humeri $(\mathrm{n}=20)$

\begin{tabular}{lccccc}
\hline $\begin{array}{l}\text { pQCT } \\
\text { measure }\end{array}$ & \multicolumn{2}{c}{ Maximum Torque } & \multicolumn{2}{c}{ Torsional Rigidity } \\
\cline { 2 - 3 } $\mathbf{R}^{\mathbf{2}}$ & P-value & & $\mathbf{R}^{\mathbf{2}}$ & P-value \\
\hline Ct.vBMD & 0.01 & $\mathrm{NS}$ & 0.04 & $\mathrm{NS}$ \\
Ct.BMC & 0.76 & $<0.001$ & 0.61 & $<0.001$ \\
Tt.Ar & 0.71 & $<0.001$ & 0.81 & $<0.001$ \\
Ct.Ar & 0.85 & $<0.001$ & 0.71 & $<0.001$ \\
Ps.Pm & 0.72 & $<0.001$ & 0.83 & $<0.001$ \\
Ec.Ps & 0.01 & $\mathrm{NS}$ & 0.07 & $\mathrm{NS}$ \\
Ct.Th & 0.50 & $<0.001$ & 0.35 & $<0.01$ \\
$\mathrm{I}_{\mathrm{P}}$ & 0.90 & $<0.001$ & 0.90 & $<0.001$ \\
SSI & 0.94 & $<0.001$ & 0.92 & $<0.001$ \\
\hline
\end{tabular}


Table 3

Overall precision measurements calculated by root mean square (RMS) method and 95\% confidence least significant change (LSC) values for 30 subjects scanned six times each (degrees of freedom $=150$ )

\begin{tabular}{|c|c|c|c|c|}
\hline \multirow{2}{*}{ pQCT measure } & \multicolumn{2}{|c|}{ RMS } & \multicolumn{2}{|c|}{ LSC } \\
\hline & Absolute (units) & Relative (\%) & Absolute (units) & Relative (\%) \\
\hline \multicolumn{5}{|l|}{ Bone measures } \\
\hline Ct.vBMD $\left(\mathrm{mg} / \mathrm{cm}^{3}\right)$ & 5.51 & 0.47 & 15.27 & 1.29 \\
\hline Ct.BMC (mg/mm) & 2.55 & 1.00 & 7.05 & 2.76 \\
\hline $\mathrm{Tt} . \mathrm{Ar}\left(\mathrm{mm}^{2}\right)$ & 3.78 & 1.02 & 10.48 & 2.82 \\
\hline Ct.Ar $\left(\mathrm{mm}^{2}\right)$ & 2.06 & 0.91 & 5.71 & 2.51 \\
\hline Ps.Pm (mm) & 0.34 & 0.50 & 0.93 & 1.39 \\
\hline Ec.Pm (mm) & 0.45 & 1.17 & 1.24 & 3.23 \\
\hline Ct.Th (mm) & 0.04 & 0.86 & 0.10 & 2.38 \\
\hline $\mathrm{I}_{\mathrm{P}}\left(\mathrm{mm}^{4}\right)$ & 252.6 & 1.40 & 699.7 & 3.88 \\
\hline $\operatorname{SSI}_{\mathrm{P}}\left(\mathrm{mm}^{3}\right)$ & 19.1 & 1.44 & 52.9 & 3.99 \\
\hline \multicolumn{5}{|l|}{ Soft tissue measures } \\
\hline Total tissue CSA $\left(\mathrm{cm}^{2}\right)$ & 1.36 & 1.86 & 3.76 & 5.16 \\
\hline \multicolumn{5}{|l|}{ Muscle } \\
\hline Absolute CSA $\left(\mathrm{cm}^{2}\right)$ & 0.61 & 1.91 & 1.69 & 5.30 \\
\hline Relative CSA (\%) & 0.46 & 1.11 & 1.26 & 3.06 \\
\hline Density $\left(\mathrm{mg} / \mathrm{cm}^{3}\right)$ & 0.58 & 0.70 & 1.60 & 1.95 \\
\hline \multicolumn{5}{|l|}{ Fat } \\
\hline Absolute CSA $\left(\mathrm{cm}^{2}\right)$ & 1.10 & 2.75 & 3.05 & 7.63 \\
\hline Relative CSA (\%) & 0.49 & 1.00 & 1.36 & 2.78 \\
\hline
\end{tabular}


Table 4

Influence of tester and timing on pQCT precision error ${ }^{a}$

\begin{tabular}{|c|c|c|c|c|c|c|c|}
\hline \multirow{2}{*}{ pQCT measure } & \multicolumn{2}{|c|}{ Within-day } & \multicolumn{2}{|c|}{ Between-day } & \multicolumn{3}{|c|}{ Two-way ANOVA results } \\
\hline & Within-tester & Between-tester & Within-tester & Between-tester & Tester & Timing & Interaction \\
\hline \multicolumn{8}{|l|}{ Bone measures } \\
\hline Ct.vBMD $\left(\mathrm{mg} / \mathrm{cm}^{3}\right)$ & $3.36 \pm 2.30$ & $4.35 \pm 3.28$ & $2.60 \pm 2.92$ & $4.77 \pm 3.26$ & $<0.01$ & NS & NS \\
\hline Ct.BMC (mg/mm) & $1.74 \pm 1.70$ & $1.97 \pm 1.69$ & $1.53 \pm 1.69$ & $1.68 \pm 1.12$ & NS & NS & NS \\
\hline Tt.Ar $\left(\mathrm{mm}^{2}\right)$ & $2.00 \pm 2.00$ & $2.02 \pm 2.06$ & $2.37 \pm 2.68$ & $2.62 \pm 3.12$ & NS & NS & NS \\
\hline Ct.Ar $\left(\mathrm{mm}^{2}\right)$ & $1.42 \pm 1.29$ & $1.63 \pm 1.38$ & $1.51 \pm 1.38$ & $1.48 \pm 1.13$ & NS & NS & NS \\
\hline Ct.Th (mm) & $0.024 \pm 0.027$ & $0.030 \pm 0.025$ & $0.029 \pm 0.024$ & $0.030 \pm 0.026$ & NS & NS & NS \\
\hline Ps.Pm (mm) & $0.19 \pm 0.19$ & $0.18 \pm 0.19$ & $0.25 \pm 0.25$ & $0.27 \pm 0.27$ & NS & NS & NS \\
\hline Ec.Pm (mm) & $0.26 \pm 0.35$ & $0.26 \pm 0.36$ & $0.37 \pm 0.45$ & $0.37 \pm 0.37$ & NS & NS & NS \\
\hline $\mathrm{I}_{\mathrm{P}}\left(\mathrm{mm}^{4}\right)$ & $147 \pm 149$ & $156 \pm 161$ & $169 \pm 195$ & $168 \pm 184$ & NS & NS & NS \\
\hline $\operatorname{SSI}_{\mathrm{P}}\left(\mathrm{mm}^{3}\right)$ & $11.6 \pm 13.0$ & $17.0 \pm 16.0$ & $14.9 \pm 12.4$ & $15.1 \pm 11.1$ & NS & NS & NS \\
\hline \multicolumn{8}{|l|}{ Soft tissue composition } \\
\hline Total tissue CSA $\left(\mathrm{cm}^{2}\right)$ & $0.66 \pm 0.53$ & $0.60 \pm 0.48$ & $1.28 \pm 0.84$ & $1.08 \pm 1.05$ & NS & $<0.001$ & NS \\
\hline \multicolumn{8}{|l|}{ Muscle } \\
\hline Absolute CSA $\left(\mathrm{cm}^{2}\right)$ & $0.29 \pm 0.23$ & $0.36 \pm 0.28$ & $0.61 \pm 0.38$ & $0.51 \pm 0.45$ & NS & $<0.001$ & NS \\
\hline Relative CSA (\%) & $0.31 \pm 0.23$ & $0.40 \pm 0.33$ & $0.43 \pm 0.37$ & $0.43 \pm 0.36$ & NS & NS & NS \\
\hline Density $\left(\mathrm{mg} / \mathrm{cm}^{3}\right)$ & $0.40 \pm 0.33$ & $0.43 \pm 0.47$ & $0.55 \pm 0.57$ & $0.55 \pm 0.51$ & NS & NS & NS \\
\hline \multicolumn{8}{|l|}{ Fat } \\
\hline Absolute CSA $\left(\mathrm{cm}^{2}\right)$ & $0.51 \pm 0.38$ & $0.48 \pm 0.35$ & $0.88 \pm 0.82$ & $0.87 \pm 0.75$ & NS & 0.001 & NS \\
\hline Relative CSA (\%) & $0.34 \pm 0.26$ & $0.39 \pm 0.33$ & $0.45 \pm 0.42$ & $0.39 \pm 0.33$ & NS & NS & NS \\
\hline
\end{tabular}

${ }^{a}$ Data indicate individual absolute precision error measurements (SD) 